\title{
Strategi Marketing Public Relations X Motorcycle
}

\author{
Muhammad Nur Ilham*, Maya Amalia Oesman Palapah \\ Prodi Public Relation, Fakultas Ilmu Komunikasi, Universitas Islam \\ Bandung, Indonesia. \\ "bromnilham@gmail.com, mayaama10403@gmail.com
}

\begin{abstract}
A company really needs the role of Marketing Public Relations to compete with its competitors. One of them is a business company in the field of fashion, namely CV. Bi-Ensi Fashionindo. In introducing one of its brands, namely FMC SpeedSupply, Marketing Public Relations conducted a program by participating in automotive events in the country and abroad. The event organized by FMC SpeedSupply is a national BBQ Ride event. With this event, Public Relations FMC SpeedSupply has a goal, namely to build Brand Awareness in the eyes of consumers. The purpose of this research is to find out how the strategies, barriers and evaluation of Marketing Public Relations through the "BBQ Ride" event conducted by FMC SpeedSupply in building Brand Awareness. The theory used in this study is three ways, namely pull, push, and pass. This research was structured using qualitative methods with a case study. While the data collection techniques were conducted by interview, observation, literature study and documentation. The results of this study found that in organizing the "BBQ Ride" event, there were several points that were explained, namely planning a strategy to determine goals, time of activities carried out, then determining the target public, then collaborating with several international and local brands. strategies to attract consumer interest and the results of the "BBQ Ride" event. There is a media optimization used by FMC SpeedSupply, namely FMC SpeedSupply using baligho media installed in several corners of the city of Bandung and using Instagram social media where Instagram has the Instagram business feature, feeds and stories to maximize its promotion. As for the obstacles and how FMC SpeedSupply overcomes them and the evaluation of FMC SpeedSupply in organizing this "BBQ Ride" event. Meanwhile, the reason why FMC SpeedSupply chose to hold the "BBQ Ride" event was to introduce this brand to the public and build brand awareness.
\end{abstract}

Keywords: Marketing Public Relations, FMC SpeedSupply. Brand Awareness.

Abstrak. Suatu Perusahaan sangatlah membutuhkan peran Marketing Public Relations untuk bersaing dengan kompetitornya. Salah satunya adalah perusahaan bisnis di bidang fashion, yaitu CV. Bi-Ensi Fesyenindo. Dalam memperkenalkan salah satu brandnya yaitu FMC SpeedSupply, Marketing Public Relations melakukan program dengan mengikuti event-event otomotif yang ada didalam negeri maupun luar negeri. Event yang diselenggarakan FMC SpeedSupply adalah event nasional BBQ Ride. Dengan adanya event tersebut, Public Relations FMC SpeedSupply memiliki tujuan yaitu membangun Brand Awareness di mata konsumen. Tujuan adanya penelitian ini untuk mengetahui bagaimana strategi, hambatan dan evaluasi dari Marketing Public Relations melalui event BBQ Ride yang dilakukan oleh FMC SpeedSupply dalam membangun Brand Awareness. Teori yang digunakan dalam penelitian ini yaitu Three ways yaitu pull, push, and pass. Penelitian ini disusun menggunakan metode kualitatif dengan pendekatan studi kasus. Sedangkan teknik pengumpulan data dilakukan dengan wawancara, observasi, studi pustaka dan dokumentasi. Hasil dari penelitian ini ditemukan bahwa dalam menyelenggarakan event "BBQ Ride" tersebut ada beberapa poin yang dijelaskan yaitu merencakakan strategi menentukan tujuan, waktu \& kegiatan yang dilakukan, lalu menentukan publik sasarannya, lalu bekerjasama dengan beberapa brand internasional maupun lokal, strategi menarik minat konsumen dan hasil dari event "BBQ Ride". Terdapat optimalisasi media yang dimanfaatkan FMC SpeedSupply yaitu FMC SpeedSupply menggukan media baligho yang dipasang dibeberapa sudut kota Bandung dan menggunakan media sosial Instagram dimana Instagram memiliki fitur Instagram business, feeds dan story untuk memaksimalkan promosinya. Adapun hambatan dan bagaimana FMC SpeedSupply menanggulanginya serta Evaluasi FMC SpeedSupply dalam menyelenggarakan event "BBQ Ride" ini. Sedangkan alasan FMC SpeedSupply memilih menyelenggarakan event "BBQ Ride" untuk memperkenalkan brand ini kepada masyarakat dan membangun brand awareness.

Kata Kunci: Marketing Public Relations, FMC SpeedSupply, Brand Awareness. 


\section{A. Pendahuluan}

Persaingan dari dunia bisnis dalam berbagai aspek di bidang fashion semakin ketat dengan banyaknya kompetitor. Hal ini dikarenakan perkembangan kebutuhan konsumen yang mulai banyak mengenali selera fashionnya. Adanya persaingan dalam usaha fashion, membuat para produsen fashion untuk meningkatkan produknya dari segi kualitas maupun pelayanan. Hal ini didasari karena semakin baik kualiatas barang dan pelayanan membuat citra nama perusahaan tersebut. Banyaknya persaingan membuat para perusahaan di bidang fashion membuat ide-ide yang inovatif dan kreatif melalui segi penjualan dan pelayanannya. Hal ini akan membuat seberapa kuat perusahaan tersebut bersaing dengan para komeptitor lainnya.

Menurut data yang dirilis dari Kementrian Perindustrian Republik Indonesia (KEMENPRIN) di tahun 2020 brand fashion yang sudah bisa dikategorikan menjadi Global Brand adalah The Executive, Eiger, dan Brodo. Tetapi melalui unggahan dari data yang dirilis oleh badan yang meneliti terkait hal pemeringkatan berbagai bidang properti dunia atau World Intellectual Property Organization (WIPO) dalam inovasi Brand Global, Indonesia di tahun 2020 menempati peringkat ke-85 dari 131 negara lainnya di dunia. Sedangkan untuk zona ASEAN, Indonesia mampu memperoleh peringkat ke-7. Poin ini menunjukan bahwa masih banyak brand fashion di Indonesia yang belum mendaptkan pengakuan lebih dan dikenal luas oleh masyarakat. Sehingga secara data yang diperoleh, mengharuskan bahwa brand-brand fashion di Indonesia meningkatkan Brand Awareness agar menndapatkan pengakuan menjadi Brand Global.

Tahun 2015 tepatnya 27 Oktober adalah lahirnya X Motorcycles lahir dari pengembangan The X. Selama 2015-2016 adalah proses pembentukan "embrio" dan research \& developement untuk X Motorcycles membuat produk sesuai dengan segmentasi pasar. Dari mulai pengumpulan ide dan referensi maupun pendekatan dengan komunitas otomotof khususnya motor di indonesia maupun mancanegara.

Salah satu cara Marketing Public Relations FMC SpeedSupply memberikan informasi dan memasarkan produknya dengan rutin mengikuti event-event komunitas motor/otomotif. Strategi yang diterapkan FMC SpeedSupply adalah Membangun hubungan emosional kedekatan dengan para komunitas dengan mesupport kegiatan dan event motor yang diselenggaran di Indonesia.

Marketing Public Relations FMC SpeedSupply sudah pernah menjelajah mengikuti event-event culture motor luar negeri. Di tahun 2016, FMC SpeedSupply menjadi brand Indonesia pertama yang mengikuti event Internasional "Yokohama Hotrod Custom Show" 2016 di Jepang. FMC SpeedSupply juga menjadi brand yang selalu bergabung dalam event disekala Asia Tenggara lainnya, yaitu dengan mengikuti event "Art Of Speed" di Malaysia. Di event nasionalnya juga FMC aktif mengikuti event yang bernama Gentlemen's Supply di Plaza Indonesia dan BBQ Ride.

BBQ Ride adalah event dengan konsep otomotif terbesar di kota Bandung. Dalam acara BBQ Ride itu dihadiri oleh masyarakat penikmat otomotif, artis lokal dan nasional, seniman, komunitas motor dan para industri kreatif dibidang motor custom lainnya. Acara BBQ Ride biasanya diisi oleh kegiatan-kegiatan seperti Talkshow, pesta BBQ, Pertunjukan musik, adapun art exhibition yang mana terkumpulnya dana nantinya akan didonasikan, dan terdapat beberapa foodtruck yang turut meramaikan suasana acara. Event BBQ Ride ini merupakan salah satu event yang dilakukan FMC SpeedSupply sebagai bentuk dari impelemntasi Public Relations, yang mana salah satu tujuannya adalah untuk lebih mengenalkan brand FMC SpeedSupply marsyarkat luas. Berdasarkan pemaparan di atas, maka peneliti tertarik untuk melakukan penelitian mengenai :

1. Bagaimana Perencanaan dari Strategi Marketing Public Relations FMC SpeedSupply berbasis Event "BBQ Ride" Dalam Membangun suatu Brand Awareness?

2. Apa yang menjadi suatu Hambatan dalam merealisasikan Strategi Marketing Public Relations FMC SpeedSupply Melalui Event "BBQ Ride" Dalam Membangun Brand Awareness?

3. Bagaimana Evaluasi Strategi Marketing Public Relations FMC SpeedSupply Melalui Event "BBQ Ride" Dalam Membangun Brand Awareness? 


\section{B. Metodologi Penelitian}

Penelitian ini merupakan penelitian kualitatif dengan pendekatan studi kasus. Kualitatif menurut Siyoto (2015:120) mengungkapkan bahwa analisis data kualitatif berhubungan dengan informasi berbentuk kata ataupun kalimat yang dihasilkan dari objek penelitian serta berkaitan dengan peristiwa yang melingkupi suatu objek penelitian.

Teknik pengumpulan data yang dilakukan dengan observasi, wawancara, sumber tertulis dan dokemtasi. Untuk teknik analisis data yang digunakan yaitu melalui reduksi data, penyajian data, dan kesimpulan atau verifikasi.

\section{Hasil Penelitian dan Pembahasan}

\section{Perencanaan dari Strategi Marketing Public Relations FMC SpeedSupply berbasis event "BBQ Ride" Dalam Membangun Brand Awareness}

FMC SpeedSupply membuat sebuah perencanaan yang dibuat untuk membangun kepercayaan konsumen. Perencanaan tersebut dijalankan oleh seorang Marketing agar brand yang sudah dibuat akan dikenal dan dapat menarik khalayak luas. Menurut Rumanti (2005:150), dikatakan bahwa Marketing Public Relations untuk memenuhi kebutuhan, keinginan customernya agar dapat berpengaruh kepada pengembangan penjualan produk atau jasa dari perusahaan tersebut. Adanya Marketing Public Relations untuk memasarkan brand yang sudah dirintis dengan berbagai cara supaya brand tersebut dapat dikenal, diminati dan dinilai baik oleh para konsumen.

1. Menentukan Program dan Sasaran

Dalam hal ini, perencanaan pertama yang dilakukan oleh FMC SpeedSupply adalah menentukan program untuk mengetahui kegiatan apa yang akan dilakukan, kapan dan di mana, apa tujuan dari kegiatan ini, dan untuk siapa kegiatan ditujukan. Sebagai merek yang relatif baru, FMC SpeedSupply menciptakan kesadaran merek melalui sebuah acara. Dengan adanya acara "BBQ Ride", FMC SpeedSupply berharap dapat lebih dikenal masyarakat luas. Menurut Ruslan Marketing Public Relations merupakan gabungan antara pelaksana program dan strategi marketing dengan aktivitas program Public Relations agar dapat memberi kepuasan terhadap customernya (dalam Maryam 2017:4). Target audience dari acara "BBQ Ride" 2019 ini adalah 5000 pengunjung dengan segmen usia dari 18-50 tahun. Tujuan diadakannya acara "BBQ Ride" FMC SpeedSupply adalah untuk memberikan wadah atau fasilitas bagi para pecinta sepeda motor dari seluruh penjuru kota melalui acara "BBQ Ride".

2. Bekerja sama dengan Brand Lain

FMC SpeedSupply melibatkan brand Internasional dari Amerika yaitu Mooneyes dan 2 brand asal Jepang yaitu Helmet Beetle dan Sukisi. Sementara untuk brand lokal dari Indonesianya seperti Pickers, Unionwell dan yang lainnya. Hal ini memiliki tujuan bagaimana brand-brand tersebut adanya kesamaan market segmentasi audience dibidang fashion culture motor. Hal itulah yang menjadi alasan kuat FMC SpeedSupply menjalin kerjasama. Terlebih hal tersebut memiliki kontribusi lebih dimana dengan adanya brand-brand tersebut mampu menarik perhatian para komunitas-komunitas atau anak-anak motor untuk menghadiri event "BBQ Ride" dan FMC SpeedSupply menunjukan bahwasannya event ini dikemas secara baik, sehingga dapat membangun brand awareness untuk FMC SpeedSupply. Hal ini bertujuan untuk mendapatkan kesadaran konsumen, merangsang, penjualan memfasilitasi komunikasi, dan membangun hubungan antar konsumen, perusahaan, dan merek menurut Haris (Afiati, 2018:30)

3. Menggunakan Media

FMC SpeedSupply menggunakan media untuk mempromosikan event "BBQ Ride". Dalam hal ini FMC SpeedSupply menggunakan media cetak baliho untuk di pasang dibeberapa titik di Kota Bandung karena sifat anak motor yang sering berkumpul, sementara media yang digunakan sebagai media utamanya yaitu media sosial Instagram. Media sosial instagram ini untuk memperkenalkan sekaligus mempromosikan diselenggarakannya event "BBQ Ride" ini. Keuntungan dari media sosial instagram yaitu bukan hanya untuk mengupload foto dan video saja, melainkan bisa juga menjadi wadah untuk mencari sesuatu yang sedang kita butuhkan dan memudahkan dalam mendapatkan dan menyebarluaskan informasi. Ini merupakan salah satu bahwa pemasaran digital menurut Kotler dan Armstrong adalah bentuk pemasaran yang berhubungan langsung kepada customer secara elektronik melalui berbagai channel (Setiyawan, 
2012: 22). Maka dari itu FMC SpeedSupply menjadikan Instagram sebagai media sosial utamanya.

4. Menarik Perhatian Konsumen

Perencanaan keempat FMC SpeedSupply membuat strategi dimana booth FMC ini dibuat secara nyentrik jika dibandingkan dengan booth-booth lainnya. Dimana FMC SpeedSupply merencanakan strategi untuk menarik perhatian para pengunjung event "BBQ Ride". FMC SpeedSupply memamerkan beberapa otomotif ekslusif milik FMC SpeedSupply seperti Triumph, Lambreta, dll, FMC SpeedSupply juga langsung mengajak para brand ambassador mereka yaitu Tora Sudiro dan Stevi Item untuk langsung hadir dalam event "BBQ Ride". Para pengunjung booth FMC SpeedSupply itu sendiri bisa ikut bermain games dengan para brand ambassador tersebut Seperti Dart Games dan Pump The Tire (memompa ban dengan pompa manual) dimana peserta wajib follow instagram @fmc_speedupply terlebih dahulu untuk bisa mengikuti games ini, peserta bisa mendapatkan hadiah langsung berupa, $t$-shirt, accesories, dan voucher. FMC SpeedSupply melakukan strategi tersebut tentu untuk mempengaruhi pendapat, sikap dan tindakan orang dengan menggunakan manipulasi psikologis sehingga orang tersebut bertindak seperti atas kehendaknya sendiri, Menurut Kamus Ilmu Komunikasi (dalam Pertiwi, 2019:6).

\section{Hambatan dalam Merealisasikan Strategi Marketing Public Relations FMC SpeedSupply Melalui Event "BBQ Ride" Dalam Membangun Brand Awareness}

1. Hambatan Eksternal

FMC SpeedSupply mengalami hambatan Ekologis/Fisik dimana hambatan ini berkaitan dengan cuaca tempat diselenggarakannya event "BBQ Ride". Karena komunikasi dapat terganggu oleh cuaca hujan, dimana suara bising hujan dapat juga mengganggu konsentrasi. Menurut Rakhmat dalam melakukan komunikasi, bukan hanya tentang pesan, akan tetapi situasi komunikator (dalam Nurdianti, 2014: 155). Sehingga mengganggu jalannya acara dan kenyamanan pengunjung.

FMC SpeedSupply juga memberikan tempat berteduh untuk para pengunjung sehingga mereka tidak kehujanan. Walaupun medan event menjadi berlumpur atau becek, akan tetapi para pengunjung kembali menimkati event "BBQ Ride" setelah hujan reda.

2. Hambatan Waktu

Hambatan yang dialami FMC SpeedSupply kemudian melibatkan pihak-pihak yang diajak bekerja sama. Karena banyaknya pihak yang terlibat seperti brand-brand lokal maupun dari luar, guest star, dan brand ambassador. Hambatan ini memang terasa kecil, akan tetapi jika diabaikan oleh FMC SpeedSupply tentu akan berdampak besar pada waktu yang sudah ditentukan. Event "BBQ Ride" ini berlangsung dari pukul 09.00 WIB - 22.00 WIB cukup tepat waktu. Dengan adanya denda sebagai bentuk hukuman jika ada pihak yang lalai dalam masalah waktu. Menurut Tubs dan Moss komunikasi dibilang efektif ketika pesan yang dimaksud berhasil dipahami oleh penerima. (Mulyana, 2005:69). Sehingga timeline event "BBQ Ride" yang sudah dikomunikasikan saat meeting bisa sesuai rencana.

3. Hambatan Media Komunikasi

Hambatan pertama yang dialami oleh FMC SpeedSupply dalam menyelenggarakan event "BBQ Ride" adalah hambatan teknis melalui media saluran komunikasi. Event yang diselenggarakan outdoor ini memicu menimbulkan hambatan komunikasi dimana terjadinya miss komunikasi antara panitia. Karena sulitnya berkomunikasi terkadang menyebabkan salahnya persepsi antara komunikator dan komunikan. Hambatan tersebut biasanya disebut Noise (Effendy, 2003:45).

FMC SpeedSupply mengatasi hal demikian dengan cara memberikan satu orang alat bantuan komunikasi yaitu handy talky. Sehingga para panitia yang berkomunikasi bisa memimalisir miss komunikasi yang kemungkinan terjadi. 


\section{Evaluasi Strategi Marketing Public Relations FMC SpeedSupply Melalui Event "BBQ Ride" Dalam Membangun Brand Awareness}

1. Evaluasi Acara

Evaluasi Menurut Wilcox yaitu tahapan pengukuran hasil sebuah program PR yang dikonfrontasikan dengan tujuan dan sasaran yang telah ditentukan sebelumnya pada tahapan perencanaan. (dalam Pudjiastuti, 2010: 69). FMC SpeedSupply beserta brand-brandnya melakukan evaluasi dengan membuat forum diskusi grup. Pengunjung event "BBQ Ride" yang sudah ditargetkan 4.000 ternyata setelah membuka data pengunjung yang hadir adalah kurang lebih 5.600 artinya target segmentasinya tercapai. FMC SpeedSupply merasa puas dengan kinerja timnya. Dimana semua pihak yang terlibat melalui perwakilannya memberikan evaluasi mereka sehingga memudahkan FMC SpeedSupply untuk dijadikan pembelajaran kedepannya dalam menyelenggarakan event-event selanjutnya.

2. Evaluasi Tempat

FMC SpeedSupply juga mengevaluasi untuk masalah penjualan diboothnya yang dirasa kurang memenuhi ekspetasi mereka biasanya karena dari cara berjualannya yang ternyata kurang maksimal. FMC SpeedSupply sendiri melakukan gesture komunikasi non-verbal seperti dengan membuat beberapa games dengan hadiah yang menarik seperti voucher diskon. Hasilpun cukup baik untuk booth FMC SpeedSupply sendiri karena melalui data penjualan selama event cukup bagus. Penjualan Merchandise di event Kaos 405 Pcs \& Topi 8 Pcs / Rp. 61.870.000 dan Spreading Voucher disc FMC sebanyak 3000 Pcs ke para pengunjung, termasuuk return voucher sebanyak 116 voucher $(3,8 \%)$. Ini mendandakan bahwa SPG yang berada dibooth dengan bantuan koleksi motor yang dipamerkan, lalu adanya beberapa artis yang hadir, dan beberapa games yang dimainkan dalam booth berhasil untuk menarik perhatian pengunjung sehingga pengunjung ramai datang ke booth FMC SpeedSupply.

3. Evaluasi Pengunjung

Untuk habbit para pengunjung event "BBQ Ride" yang mana mayoritasnya anak motor, tentu mereka ini memiliki kebiasaan ataupun kesenangan tersendiri. FMC SpeedSupply melakukan pendekatan komunitas kepada para club-club atau anak-anak motor agar mengetahui apa saja kebutuhan mereka dalam event ini.

FMC SpeedSupply menjadikan evaluasi ini untuk memuaskan para pengunjung event "BBQ Ride". Karena dengan dipenuhi segala kebutuhan dan keinginnya tentu akan mampu meningkatkan penilaian terhadap brand FMC SpeedSupply. Karena kebutuhan dan keinginan customer yang harus diperhatikan. (Ruslan, 2006:255). Hal ini pun berdampak positif karena FMC SpeedSupply mendapat pengakuan bahwa menggelar event ini tidak main-main. Evaluasi ini dilakukan dengan melakukan penilaian atau persiapan, implementasi, dan hasil dari program.

\section{Kesimpulan}

Perencanaan strategi marketing public relations yang dilakukan FMC SpeedSupply yang pertama adalah menentukan dan merencanakan event "BBQ Ride". Tujuan utama FMC SpeedSupply menyelenggarakan event ini adalah karena brand ini adalah brand yang baru lahir sehingga ingin membangun brand awareness dengan tujuan brand ini lebih dikenal lebih luas oleh konsumen atau masyarakat luas. Kemudian FMC SpeedSupply dalam menyelenggarakan event ini melibatkan atau menjalin kerja sama dengan brand-brand lain atau pihak sehingga event ini mampu menarik lebih banyak calon pengunjung, Selanjutnya FMC SpeedSupply menggunakan bantuan media untuk mempublikasikan event "BBQ Ride" ini. Dan yang terakhir FMC merancang beberapa program dalam event "BBQ Ride" ini untuk menarik perhatian pengunjung.

Dalam menyelenggarakan event "BBQ Ride" ini FMC SpeedSupply tidak lepas dalam mengalami beberapa hambatan.FMC SpeedSupply mengalama hambatan eksternal atau Ekologis seperti dari cuaca hujan, lalu ada hambatan mengenai waktu dimana event ini melibatkan banyak pihak oleh karena itu untuk meminimalisir FMC SpeedSupply membuat aturan-aturan sehingga para pihak-pihak yang bekerja sama mampu berjalan sesuai perjanjian dan menghargai waktu, dan yang terkahir ada hambatan media komunikasi yaitu selama menggunakan handy talky selama event berlangsung masih terdapat beberapa miss komunikasi 
yang terjadi akibat dari noise yang berasal dari suara kebisingin hujan ataupun acara. Akan tetapi FMC SpeedSupply mampu menangani hambatan-hambatan ini sehingga event ini berjalan cukup baik.

Evaluasi sebagai bentuk langkah akhir yang dilakukan FMC SpeedSupply dalam event "BBQ Ride" untuk mengetahui apa saja yang menjadi kekurangan selama event berlangsung. FMC SpeedSupply mengevaluasi acara, waktu, pengunjung. Untuk evaluasi acara, Evaluasi acara disini FMC SpeedSupply membuat forum discussion dengan para pihak yang sudah menjalin bekerja sama untuk sama-sama belajar satu sama lain dan untuk pembelajaran ketika ada event selanjutnya. Lalu evaluasi waktu, disini bagaimana melalui booth yang sudah disediakan untuk melakukan program apa saja dalam waktu kapan saja untuk menarik perhatian pengunjung. Yang terakhir FMC SpeedSupply mengevaluasi pengunjung dimana FMC SpeedSupply mempelajari habbit para pengunjung ini melalui kebiasaannya untuk memenuhi kebutuhannya di eventevent selanjutnya.

\section{Acknowledge}

Peneliti ingin mengucapkan terima kasih kepada dosen pembiming yaitu Ibu Maya Amalia Oesman P., S. Pd., M. Si. telah bersedia membimbing peneliti sehingga akhirnya dapat menyelesaikan artikel ilmiah ini dan juga kepada berbagai pihak yang telah membantu yang tidak bisa disebutkan satu persatu.

\section{Daftar Pustaka}

[1] Ardianto, Elvinaro. Public Relations Praktis. Bandung: Widya Padjajaran. 2008

[2] Cutlip, Scott, Broom.Glen. M., and Center Allen H M. Effective Public Relations. Ed.9. Jakarta: Kencana, 2009.

[3] Maryam. 2017. "Strategi Marketing Public Relations Dalam Meningkatkan Jumlah Tamu Hotel Pantai Marina Bengkalis". Jurnal FISIP. Vol. 4, No.2.

[4] Mulyana, Deddy. (2008). Ilmu Komunikasi: Suatu Pengantar. Bandung: Remaja Rosdakarya.

[5] Nurdianti, Siti. R. 2014. "Analisis Faktor-Faktor Hambatan Komunikasi Dalam Sosialisasi Program Keluarga Berencana Pada Masyarakat Kebon Agungsamarinda”. Jurnal Ilmu Komunikasi. Vol, 2. No. 2: 145-159.

[6] Rachmawati, A. R., W. Drajat, and Paryati. "Strategi Marketing Public Relations Daarut Tauhid Dalam Mempertahankan Loyalitas Jamaah.” Jurnal Ilmu Hubungan Masyarakat 3, no. 3 (2018)

[7] Rosady Ruslan. (2005). Manajemen Humas dan Komunikasi Konsepsi dan Aplikasi Edisi Revisi. Jakarta: PT. Raja Grafindo.

[8] Rumanti, Maria Assumpta. 2002. Dasar-dasar Public Relations Teori dan

[9] Praktik. Jakarta: PT Gramedia Widiasarana Indonesia.

[10] Yulianita, Neni. Dasar-Dasar Public Relations. Bandung: Pusat Penerbit Universitas (P2U), 2012. 